hospital. From January 1990 through February 1991, 10 patients developed tuberculosis and five patients died, prompting an investigation of possible nosocomial transmission. Mycobacterium tuberculosis isolates from the patients were compared by restriction fragment length polymorphism (RFLP) by a polymerase chain reaction method. The source case was a renal transplant patient who had post-transplant exposure at another hospital. The source patient was subsequently rehospitalized on the renal transplant unit; the diagnosis of TB and institution of isolation precautions were delayed.

Epidemiologic and RFLP analysis showed transmission from the source patient to five other renal transplant patients and one HIV-infected patient. $M$ tuberculosis isolates from another four patients had other RFLP patterns. The median incubation period for TB in renal transplant patients was 7.5 weeks (range, 5 to 11). Bronchoscopy and intubation of the source patient and inadequate ventilation on the renal transplant unit are believed to have increased the risk of transmission in this outbreak. 1224.

FROM: Jereb JA, et al. J Infect Dis 1993;168:1219-

\section{Increase in Coccidioidomycosis Cases Reported Following California Earthquake}

Following the January 17, 1994, earthquake in Los Angeles, more than 30 cases of coccidioidomycosis have been reported. The outbreak is unusual because it was precipitated by the earthquake rather than the more typical cause, drought and wind that results in the release of the dustborne fungus. The 6.7 magnitude earthquake and its aftershocks produced large clouds of dust in the San Fernando Valley.

Coccidioidomycosis, often referred to as "valley fever," mostly affects residents of rural areas of the Southwest, a parched region where the fungus thrives in the soil. One of the worst outbreaks of the disease occurred in 1977 in central California's heavily agricultural San Joaquin valley, where during a bad drought the fever killed at least 20 people.

FROM: New York Times February 23, 1994.

\section{Joint Commission's 1994 Ambulatory Care Manual Includes Quality Improvement and Infection Control Standards}

The Joint Commission on Accreditation of Health
Care Organizations' 1994 Accreditation M anual for A mbulatory $\mathrm{H}$ ealth Care has new standards defining the role of organization leaders in quality assessment and improvement activities, a new chapter on infection control, and revised scoring guidelines that address key issues related to the granting of clinical privileges. Ginger Whitlock, director of Joint Commission's Office of Ambulatory Care Accreditation Services, said, "The standards on the surveillance and control of infections have been combined into a single chapter to foster a more systematic approach to this important function."

\section{AAMI Issues New Document on Shipping Contaminated Devices}

The Association for the Advancement of Medical Instrumentation (AAMI) has published a new document, Safe $\mathrm{H}$ andling of Biologically Contaminated $M$ edical Devices in Nonclinical and Clinical Settings, approved in December 1993, that provides guidance for the safe handling and decontamination of devices that are returned to the manufacturer or a third party (eg, a test house) for servicing or for evaluation of suspected malfunctions. Such devices pose health hazards to postal/shipping personnel and to the manufacturer's employees and are subject to special decontamination and labeling requirements under the Occupational Safety and Health Administrations's bloodborne pathogen standard.

The AAMI report contains recommendations both for the hospital personnel who must prepare contaminated devices for shipping and for the manufacturer's representatives who are responsible for receiving and servicing such equipment. The new publication also includes special considerations applying to devices that are transferred from hospital to hospital or that require in-hospital repair/servicing by the manufacturer's representatives or clinical biomedical engineering personnel.

AAMI also has published a new edition of its standard, Good H ospital Practice: Steam Sterilization and Sterility Assurance, that provides guidance for hospitals and healthcare facilities.

To order, contact Tiffany Rubinstein (extension 217) at (800) 332-2264 or (703) 5254890. Order codes: Safe Handling of Contaminated Devices: TIR10-006MM; Steam Sterilization: ST46-006-MM).

\section{Female- to-Female Sexual Transmission of HIV Reported}

Dr. Josiah D. Rich and colleagues from Boston's Brigham and Women's Hospital recently reported 